\title{
Coding Challenges in Common Pediatric Sports Surgeries of the Shoulder, Elbow, and Ankle
}

Emily L. Niu, MD'1; Sarah Wiskerchen, MBA, CPC²; Jennifer J. Beck, MD³; Aristides I. Cruz, Jr., MD, MBA ${ }^{4}$; POSNA QSVI Sports Committee*

${ }^{1}$ Children's National Hospital, Washington, DC; ${ }^{2}$ Karen Zupko \& Associates, Inc., Chicago, IL; ${ }^{3}$ Orthopaedic Institute for Children/UCLA, Los Angeles, CA; ${ }^{4}$ Hasbro Children's Hospital, Providence, RI

Correspondence to: Emily L. Niu, MD; Children's National Hospital, 111 Michigan Ave. NW, Washington, DC 20010,

E-mail: eniu@childrensnational.org

Received: January 7, 2022; Accepted: January 8, 2022; Published: February 1, 2022

DOI: 10.55275/JPOSNA-2022-0003

\section{Introduction}

Pediatric Sports Medicine is a relatively new subspecialty within Pediatric Orthopaedics, with continually evolving surgical techniques. As a result, many of the procedures performed may not have well-established corresponding CPT codes, leading to considerable variability in how different surgeons code for the same procedure.

This article presents case scenarios for common shoulder, elbow, and ankle pathologies treated surgically by pediatric orthopaedic surgeons. The intent is to clarify some discrepancies in coding for these procedures and aid the surgeon in proper billing. It is important to note that the following scenarios are hypothetical and therefore ultimate code selection should always reflect the operative report documentation.

\section{Case 1: Shoulder Instability}

A 17-year-old male presents with traumatic anterior shoulder instability and is undergoing shoulder stabilization procedure.

\section{What is the correct CPT coding for arthroscopic Bankart (anteroinferior labrum repair) versus open Bankart repair?}

Arthroscopic Bankart repair is reported using CPT code 29806 (Arthroscopy, shoulder, surgical; capsulorrhaphy). There are several CPT codes that describe open capsulorrhaphy and/or labral repair procedures, in the range of 23450-23466. The codes are differentiated by various factors, such as procedure type (e.g., labral repair, bone block, coracoid process transfer), and location (e.g., anterior or posterior). An open capsulorrhaphy with labral repair is reported using code 23455 (Capsulorrhaphy, anterior; with labral repair (e.g., Bankart procedure)).

\section{If open Bankart repair is performed in conjunction with a capsular shift for multidirectional instability, what is the correct code?}


Open repair of capsular shift for multidirectional instability would be reported using code 23466 (Capsulorrhaphy, glenohumeral joint, any type multidirectional instability); under AAOS global service data guidelines, 23466 includes the work of 23455 , defined above.

\section{If both an arthroscopic Bankart and SLAP} repair are performed, are these codes separately reportable?

Under CPT guidelines, arthroscopic Bankart and SLAP repair are defined by codes 29806 (Arthroscopy, shoulder, surgical; capsulorrhaphy) and 29807 (Arthroscopy, shoulder, surgical; repair of SLAP lesion). Under AAOS global service guidelines, both codes are reportable with appropriate supporting diagnoses. A challenge currently facing orthopaedic surgeons is the fact that the Centers for Medicare and Medicaid Services (CMS) has established a set of reimbursement policies called the National Correct Coding Initiative (NCCI), and the edits and guidelines of NCCI restrict reporting both of these codes in the same shoulder during a single operative session. NCCI was created by CMS in 1996 for the Medicare program, but nongovernment payors and large medical institutions frequently cite NCCI as an element of their own reimbursement and/or coding policies, and NCCI is also used for state Medicaid programs. This can result in reimbursement losses for adolescent patients who require both procedures.

\section{If a more extensive arthroscopic labral repair is performed (i.e., repair of the posterior labrum in addition to Bankart), is this coded differently from a standard arthroscopic Bankart repair?}

There is no CPT code for Bankart repair of both the anterior inferior and posterior inferior labrum. Because the CPT vignette for 29806 (Arthroscopy, shoulder, surgical; capsulorrhaphy) describes an anterior repair, physicians could potentially use increased procedural services modifier $\mathbf{- 2 2}$ when the posterior labrum is additionally repaired. The operative report should support the use of this modifier by detailing reasoning for increased intensity, time, technical difficulty of the procedure, severity of the patient's condition, and/ or physical and mental effort required. For example, the operative report should state that due to the larger size and increased severity of the labral tear, the repair required additional time and use of additional accessory portals and additional suture anchors to adequately complete, thereby making the procedure more technically difficult and requiring more time.

\section{If there is a bony Bankart (fracture of the} antero-inferior glenoid with associated labrum tear) that is repaired arthroscopically, how is this coded?

There is no category I CPT code for this procedure. We typically suggest 29806 (Arthroscopy, shoulder, surgical; capsulorrhaphy) with increased procedural services modifier -22, such as when arthroscopic labral repair serves as an indirect reduction maneuver for the glenoid rim fracture. Code 29999 (Unlisted procedure, arthroscopy) could also be considered.

If a bony Bankart is repaired through an open approach, can this be coded as open reduction and internal fixation of a glenoid fracture?

If additional labral repair or capsular shift is performed during this procedure, can these be reported separately?

Yes, code 23585 (Open treatment of scapular fracture (body, glenoid or acromion) includes internal fixation, when performed) could be used when open reduction is performed. The AAOS global service data guidelines for code 23585 do not include labral repair or capsular shift techniques, so they could potentially be separately reportable.

If an arthroscopic remplissage is performed in addition to labrum repair, can this be coded as a rotator cuff repair or as a tendon transfer procedure?

To date, the AMA has not commented on this procedure in CPT Assistant. In 2016, the AHA publication Coding 
Clinic for HCPCS suggested reporting 29999 (Unlisted procedure, arthroscopy) in conjunction with 29806 (Arthroscopy, shoulder, surgical; capsulorrhaphy) when both arthroscopic labral repair and remplissage were performed. Some payors commonly deny remplissage as an unlisted procedure, and an alternate approach is to report the work using increased procedural services modifier -22 . The work of remplissage is not consistent with a rotator cuff repair or a tendon transfer.

\section{If a Latarjet procedure is performed in conjunction with a diagnostic arthroscopy, are these coded separately?}

If bone graft other than coracoid is used (e.g., distal tibia allograft) how is this coded?

If a coracoid bone block is used for the open Latarjet procedure, CPT code 23462 (Capsulorrhaphy, anterior, any type; with coracoid process transfer) is most appropriate. Under AAOS global service guidelines, 23462 includes diagnostic arthroscopy in the shoulder (29805). Instead of relying on the term Latarjet, the physician should describe the type of bone block used. An anterior procedure with an allograft bone block would be reported using code 23460 (Capsulorrhaphy, anterior, any type; with bone block).

\section{Case 2: Osteochondritis Dissecans (OCD) of the Elbow}

A 14-year-old male diagnosed with capitellar OCD with concern for instability on imaging is undergoing surgical treatment.

\section{What is the correct CPT coding for arthroscopic versus open drilling of the elbow OCD? \\ If the OCD is found to be unstable but in situ and repair is performed, what is the correct coding for arthroscopic versus open in situ drilling and repair?}

There are no category I CPT codes for either procedure. Code 24999 (Unlisted procedure, humerus or elbow) would be used for an open technique or code 29999
(Unlisted procedure, arthroscopy) for an arthroscopic technique. The comparable procedures described for treatment of knee OCD could be considered for comparison.

If the OCD fragment is found to be completely detached, and reduction and repair is performed, how is this billed for arthroscopic versus open repair, respectively?

If the loose OCD fragment is retrieved either arthroscopically or open, can this be billed separately?

If bone graft (autograft) is obtained and used to backfill the defect prior to repair, how is this billed?

There are no category I CPT codes for either procedure. Code 24999 (Unlisted procedure, humerus or elbow) would be used for an open technique or code 29999 (Unlisted procedure, arthroscopy) for an arthroscopic technique. The knee procedures could be considered for comparison. For the knee, the comparable procedure is billed using code 29885 (Arthroscopy, knee, surgical; drilling for osteochondritis dissecans with bone grafting, with or without internal fixation (including debridement of base of lesion)), which describes arthroscopic drilling to promote bleeding and subsequent healing, the use of bone graft, and internal fixation if it is used. Note that bone grafting is not separately billable.

In the knee, if an osteochondral fragment is removed in conjunction with codes 29885, 29886, or 29887 (arthroscopic treatment of osteochondritis dissecans), CPT guidelines introduced in 2021 would allow reporting of code 29874 (Arthroscopy, knee, surgical; for removal of loose body or foreign body (e.g., osteochondritis dissecans fragmentation, chondral fragmentation)) only if the loose body is equal to or larger than the diameter of the arthroscopic cannula(s) used for the specific procedure, is removed through a separate incision, or is removed through a portal that has been enlarged to allow removal of the loose or foreign bodies. Similarly, for the elbow, arthroscopic osteochondral fragment loose body 
removal (29834) may be reported as a separate code if the above CPT criteria are met.

\section{If open osteochondral autograft transplant (OAT) procedure is performed from the ipsilateral knee to the elbow, what is the correct coding?}

\section{Can harvesting of the osteochondral autograft from the knee be coded separately?}

\section{If the lateral ulnar collateral ligament is detached for better exposure during the approach, and repaired at the end of the case, can a ligament repair procedure be coded?}

There is no category I CPT code for either procedure. Code 24999 (Unlisted procedure, humerus or elbow) would be used for an open technique. Code 27416 (Osteochondral autograft(s), knee, open (e.g., mosaicplasty) (includes harvesting of autograft[s])) could be considered for comparison. Note that the definition of 27416 states "includes harvesting of autograft[s]," thus harvesting during the same operative session would not be separately reportable. Repair of the lateral ulnar collateral ligament that was detached for access would be considered inclusive to any other billed procedure.

\section{In all the above scenarios, if arthroscopy is performed first and then converted to open procedure, can a diagnostic arthroscopy be billed separately?}

No, under AAOS global service guidelines, open elbow procedures include diagnostic arthroscopy, 29830. If an unlisted code is billed, referring to a comparison code from another anatomic site, such as the knee, the comparison code similarly includes diagnostic arthroscopy.

\section{Case 3: Ankle Instability}

A 16-year-old male with history of traumatic low ankle sprain is undergoing stabilization procedure.

What is the correct CPT coding for lateral ankle ligament (ATFL and CFL) repair (Brostrom procedure) versus tendon transfer procedure (i.e., Watson-Jones or Chrisman-Snook)?

There are three CPT codes used for ligament repair in the ankle: 27695 (Repair, primary, disrupted ligament, ankle; collateral, 27696 (Repair, primary, disrupted ligament, ankle; both collateral ligaments), and 27698 (Repair, secondary, disrupted ligament, ankle, collateral (e.g., Watson-Jones procedure)). Codes 27695 and 27696 are used for primary repairs, and 27698 is used for secondary repair. CPT Assistant, a publication of the AMA, has given several examples of the term secondary, including re-do or re-entry into the body area, chronic injury repair, and when other tissue is used to achieve the repair because a direct repair is no longer possible.

In the scenario above, a key question is whether the tear is chronic. If it is a primary, acute repair, then a direct repair would be treated as primary, and a single unit of code 27695 would apply. If the status is chronic, then based on a CPT Assistant Q\&A published in March 2014, code 27698 would be used.

If autograft (i.e., peroneus brevis) is harvested and used for tendon transfer, is the harvest a separately reportable procedure?

\section{If autograft is harvested through a separate incision from the reconstruction procedure, is this separately reported?}

If the repair is performed using a tendon autograft, then code 27698 would similarly be used; notice that a Watson-Jones technique is one of the examples used by CPT in the 27698 definition. Under AAOS global service guidelines, use of a local tendon autograft is inclusive to code 27698, but harvest from a distant site would be coded using 20924 (Tendon graft, from a distance (e.g., palmaris, toe extensor, plantaris)).

If diagnostic ankle arthroscopy is performed prior to lateral ligament stabilization, is the arthroscopy reported separately? 
What if ankle arthroscopy with synovectomy is performed? Chondroplasty? Loose body excision (using a separate or enlarged incision)?

An arthroscopic service could be reportable if a pathology is present but would not be reported only for a "look and see." When supporting diagnoses and documentation is present, code options for these procedures are 29895 (Arthroscopy, ankle, surgical; synovectomy, partial), 29897 (Arthroscopy, ankle (tibiotalar and fibulotalar joints), surgical; debridement, limited), 29898 (Arthroscopy, ankle (tibiotalar and fibulotalar joints), surgical; debridement, extensive), and 29894 (Arthroscopy, ankle, surgical; for removal of loose body or foreign body (e.g., osteochondritis dissecans fragmentation, chondral fragmentation)). Note that the loose body must be equal to or larger than the diameter of the arthroscopic cannula(s) used for the specific procedure, removed through a separate incision, or removed through a portal that has been enlarged to allow removal of the loose or foreign bodies in order to justify a separate CPT code according to $\mathrm{CPT}$ guidelines.

\section{If the ligament repair is performed}

arthroscopically, how is this coded?

There is no CPT code for arthroscopic ligament repair; code 29999 (Unlisted procedure, arthroscopy) would be used for this technique.

If stable osteochondritis dissecans (OCD) of the talus is treated with arthroscopic drilling, how is this coded?

CPT code 29891 (Arthroscopy, ankle, surgical, excision of osteochondral defect of talus and/or tibia, including drilling of the defect) would be used for this procedure.

If an osteochondral fracture of the talus (acute injury that occurred at the same time as the ankle sprain) is found during ankle arthroscopy and reduction and repair is performed, how is this coded if the fracture repair procedure is performed arthroscopically?

CPT code 29892 (Arthroscopically aided repair of large osteochondritis dissecans lesion, talar dome fracture, or tibial plafond fracture, with or without internal fixation (includes arthroscopy)) could be considered in this scenario.

\section{If an open reduction internal fixation is performed, how is this coded?}

Code 28445 (Open treatment of talus fracture, includes internal fixation, when performed) is defined to represent ORIF of a talus fracture.

If the fracture fragment is removed arthroscopically and microfracture is performed to the defect instead, how is this coded?

Although code 29891, defined above, uses the word "drilling," and not the word microfracture, it is understood to represent both arthroscopic techniques.

The AAOS global service guideline for 29891 states that arthroscopic removal of a loose or foreign body is not included when it meets the CPT criteria established in 2021. The criteria include when the loose or foreign body(ies) is equal to or larger than the diameter of the arthroscopic cannula(s) used for the specific procedure, or through a separate incision, or through a portal that has been enlarged to allow removal of the loose or foreign bodies. If these criteria are met, they should be documented in the operative report and loose body arthroscopic retrieval is separately coded using 29894 (Arthroscopy, ankle, surgical; for removal of loose body or foreign body (e.g., osteochondritis dissecans fragmentation, chondral fragmentation)).

If osteochondral autograft transplant (OATs) is performed to the fracture defect, how is this coded when the procedure is performed arthroscopically? How is it coded if the procedure is performed open? 
There is no CPT code for an arthroscopic OATs procedure of the ankle; this is another example where code 29999 (Unlisted procedure, arthroscopy) would apply. If an OATs procedure with autograft is performed at the ankle using an open technique, code 28446 (Open osteochondral autograft, talus (includes obtaining graft [s])) is used.

\section{If the autograft is harvested from the knee, is this coded as a separate procedure?}

The definition of code 28446 states "includes obtaining graft[s]." This means that it is not appropriate to report a graft harvest code separately, even though it is from a distant site. The AAOS has advised, however, that 28446 is reportable even if the autograft is taken from a local site.

\section{How is this coded if allograft is used for the osteochondral transplant?}

In October 2010, CPT Assistant advised if an allograft is used for an open technique OATs procedure, code 28899 (Unlisted procedure, foot or toes) would be used.

\section{If an osteotomy (i.e., of the medial malleolus) is performed to perform the open OATs, is this a separately coded procedure?}

Under CPT and AAOS guidelines, procedures performed to gain exposure/access to the graft site are not separately coded.

\section{Summary}

Proper coding and billing of Sports Medicine procedures requires accurate and specific documentation. This should include acuity of the injury, description of the pathology being treated, and treatment techniques. It is important to note that in the majority of cases, initial diagnostic arthroscopy prior to conversion to open procedure is included in the code for the open procedure; therefore, it cannot be billed separately. In the shoulder, certain procedures such as arthroscopic bony Bankart repair or remplissage, do not have specific associated codes and may require either reporting as unlisted procedures or using modifier -22 with the justification detailed in the operative report. When treating OCD of the elbow and ankle, many of these procedures can only be billed using unlisted codes, and it may be necessary to reference the comparable procedure (typically of the knee) when documenting the procedure. Table 1 provides a summary of coding sequences for the above case scenarios and may serve as a guide to accurate CPT coding.

*POSNA QSVI Sports Committee: Jennifer J. Beck, MD; Sasha Carsen, MD, FRCSC; Allison E. Crepeau, MD; Aristides I. Cruz Jr., MD; Matthew D. Ellington, MD; Henry B. Ellis, MD; Stephanie Watson Mayer, MD; Emily L. Niu, MD; Andrew T. Pennock, MD; Zachary S. Stinson, MD; Curtis D. Vandenberg, MD 
Case 1: Shoulder Instability

\begin{tabular}{|c|c|c|c|c|c|c|}
\hline Procedure & CPT Code & Work RVU & MP RVU & PE RVU & \begin{tabular}{|c|}
2022 \\
Facility \\
Total RVU*
\end{tabular} & $\begin{array}{c}2021 \\
\text { Facility } \\
\text { Total RVU* }\end{array}$ \\
\hline Arthroscopic Bankart Repair & 29806 & 15.14 & 3.02 & 13.28 & 31.44 & 31.20 \\
\hline$w / S L A P$ repair & $\begin{array}{l}\text { Add } 29807 \\
\text { Reporting of both codes together } \\
\text { may be restricted by NCCI } \\
\text { guidelines }\end{array}$ & 14.67 & 2.92 & 13.08 & 30.67 & 30.49 \\
\hline w/posterior labral repair & Add Modifier -22 & - & - & - & - & - \\
\hline w/arthroscopic Remplissage & $\begin{array}{l}\text { Add } 29999 \\
\frac{O R}{\text { Modifier }-22}\end{array}$ & - & - & - & - & - \\
\hline $\begin{array}{l}\text { Open Bankart Repair (open } \\
\text { capsulorrhaphy with labral } \\
\text { repair) }\end{array}$ & 23455 & 14.67 & 2.94 & 11.88 & 29.49 & 29.32 \\
\hline $\begin{array}{l}\text { w/ shoulder arthroscopy } \\
\text { diagnostic }\end{array}$ & \multicolumn{6}{|l|}{ Included in 23455} \\
\hline $\begin{array}{l}\text { w/capsular shift (e.g., for } \\
\text { multidirectional instability) }\end{array}$ & $\begin{array}{l}23466 \text { ONLY } \\
\mathbf{2 3 4 6 6} \text { includes the work of } \mathbf{2 3 4 5 5}\end{array}$ & 15.80 & 3.22 & 14.23 & 33.25 & 32.95 \\
\hline $\begin{array}{l}\text { Arthroscopic bony Bankart } \\
\text { repair (fracture of the } \\
\text { anteroinferior glenoid) }\end{array}$ & $\begin{array}{l}29806+\text { modifier }-22 \\
\frac{O R}{29999}\end{array}$ & 15.14 & 3.02 & 13.28 & 31.44 & 31.20 \\
\hline Open bony Bankart repair & 23585 & 14.23 & 2.85 & 11.99 & 29.07 & 28.80 \\
\hline w/capsular shift & Add 23466 & 15.80 & 3.22 & 14.23 & 33.25 & 32.95 \\
\hline w/labral repair & Add 23455 & 14.67 & 2.94 & 11.88 & 29.49 & 29.32 \\
\hline Latarjet procedure & \multicolumn{6}{|c|}{ coding is based on the type of bone block; operative report should not rely on the term "Latarjet" } \\
\hline w/coracid process transfer & 23462 & 15.72 & 3.24 & 12.73 & 31.69 & 31.50 \\
\hline $\begin{array}{l}\text { w/bone block other than coracoid } \\
\text { (e.g., distal tibial allograft) }\end{array}$ & 23460 & 15.82 & 3.27 & 13.30 & 32.39 & 32.17 \\
\hline $\begin{array}{l}\text { w/shoulder arthroscopy } \\
\text { diagnostic }\end{array}$ & \multicolumn{6}{|l|}{ Included in 23462} \\
\hline
\end{tabular}




\section{Case 2: Unstable Osteochondritis Dissecans of Elbow}

\begin{tabular}{|c|c|c|c|c|c|c|}
\hline Procedure & CPT Code & Work RVU & MP RVU & PE RVU & \begin{tabular}{|c|}
2022 \\
Facility \\
Total RVU*
\end{tabular} & $\begin{array}{c}2021 \\
\text { Facility } \\
\text { Total RVU* }\end{array}$ \\
\hline $\begin{array}{l}\text { Arthroscopic drilling of stable OCD of } \\
\text { capitellum }\end{array}$ & 29999 & - & - & - & - & - \\
\hline $\begin{array}{l}\text { Arthroscopic drilling and in situ } \\
\text { repair of OCD }\end{array}$ & 29999 & - & - & - & - & - \\
\hline Arthroscopic repair of unstable OCD & 29999 & - & - & - & - & - \\
\hline $\begin{array}{l}\text { w/elbow arthroscopy, removal of loose } \\
\text { body }\end{array}$ & $\begin{array}{l}\text { Add } 29834 \\
\text { If CPT criteria met }\end{array}$ & 6.42 & 1.24 & 7.00 & 14.66 & 14.61 \\
\hline Open drilling of stable OCD & 24999 & - & - & - & - & - \\
\hline $\begin{array}{l}\text { Open drilling and in situ repair of } \\
\text { OCD }\end{array}$ & 24999 & - & - & - & - & - \\
\hline $\begin{array}{l}\text { Open repair with internal fixation of } \\
\text { unstable OCD with and without bone } \\
\text { graft }\end{array}$ & $\begin{array}{l}24999 \\
\text { Bone autograft harvest is } \\
\text { not separately reportable }\end{array}$ & - & - & - & - & - \\
\hline $\begin{array}{l}\text { Open Autograft OAT for treatment of } \\
\text { unstable OCD (graft from the knee) }\end{array}$ & 24999 & - & - & - & - & - \\
\hline $\begin{array}{l}\text { w/repair of LCL detached during } \\
\text { exposure }\end{array}$ & \multicolumn{6}{|c|}{ Included in 24999 , not separately reportable } \\
\hline \multicolumn{7}{|l|}{$\begin{array}{l}\text { For all open elbow procedures listed } \\
\text { above }\end{array}$} \\
\hline w/elbow arthroscopy diagnostic & Included in 24999 & & & & & \\
\hline $\begin{array}{l}\text { w/elbow arthroscopy, removal of loose } \\
\text { body }\end{array}$ & $\begin{array}{l}\text { Add } 29834 \\
\text { If CPT criteria met }\end{array}$ & 6.42 & 1.24 & 7.00 & 14.66 & 14.61 \\
\hline
\end{tabular}


Case 3: Ankle Instability

\begin{tabular}{|c|c|c|c|c|c|c|}
\hline Procedure & CPT Code & Work RVU & MP RVU & PE RVU & $\begin{array}{c}2022 \\
\text { Facility } \\
\text { Total RVU* }\end{array}$ & $\begin{array}{c}2021 \\
\text { Facility } \\
\text { Total RVU* }\end{array}$ \\
\hline \multicolumn{7}{|l|}{$\begin{array}{l}\text { Open ankle ligament repair (acute } \\
\text { primary repair) }\end{array}$} \\
\hline single ligament & 27695 & 6.70 & 1.00 & 6.53 & 14.23 & 13.99 \\
\hline both collateral ligaments & 27696 & 8.58 & 1.16 & 6.52 & 16.26 & 16.22 \\
\hline $\begin{array}{l}\text { Open lateral ankle ligament } \\
\text { reconstruction (or chronic repair } \\
\text { or revision) }\end{array}$ & 27698 & 9.61 & 1.49 & 7.79 & 18.89 & 18.79 \\
\hline $\begin{array}{l}\text { w/local tendon autograft harvest for } \\
\text { reconstruction }\end{array}$ & \multicolumn{6}{|c|}{ Included in 27695,27696 , and 27698} \\
\hline $\begin{array}{l}\text { w/distant site tendon autograft } \\
\text { harvest for reconstruction }\end{array}$ & Add 20924 & 6.68 & 1.25 & 7.06 & 14.99 & 14.93 \\
\hline \multicolumn{7}{|c|}{ Performed in conjunction with open ligament repair/reconstruction procedures } \\
\hline w/diagnostic arthroscopy & \multicolumn{6}{|c|}{ Included in 27695,27696 , and 27698} \\
\hline $\begin{array}{l}\text { w/ankle arthroscopy and } \\
\text { synovectomy }\end{array}$ & Add 29895 & 7.13 & 1.02 & 5.72 & 13.87 & 13.75 \\
\hline $\begin{array}{l}\text { w/ankle arthroscopy and } \\
\text { chondroplasty (limited) }\end{array}$ & Add 29897 & 7.32 & 1.11 & 6.16 & 14.59 & 14.62 \\
\hline $\begin{array}{l}\text { w/ankle arthroscopy and } \\
\text { chondroplasty (extensive) }\end{array}$ & Add 29898 & 8.49 & 1.26 & 6.88 & 16.63 & 16.49 \\
\hline $\begin{array}{l}\text { w/ankle arthroscopy and loose body } \\
\text { excision }\end{array}$ & $\begin{array}{l}\text { Add } 29894 \\
\text { If CPT criteria met }\end{array}$ & 7.35 & 1.18 & 6.43 & 14.96 & 14.67 \\
\hline $\begin{array}{l}\text { w/arthroscopic drilling of stable } \\
\text { OCD of the talus }\end{array}$ & Add 29891 & 9.67 & 1.55 & 8.65 & 19.87 & 19.75 \\
\hline $\begin{array}{l}\text { w/arthroscopic repair of } \\
\text { osteochondral fracture of the talus }\end{array}$ & Add 29892 & 10.27 & 1.24 & 7.31 & 18.82 & 18.94 \\
\hline $\begin{array}{l}\text { w/open repair of osteochondral } \\
\text { fracture of the talus }\end{array}$ & Add 28445 & 15.76 & 2.50 & 12.02 & 30.28 & 30.20 \\
\hline $\begin{array}{l}\text { w/open osteochondral autograft } \\
\text { transplant }(O A T S) \text { to talus }\end{array}$ & $\begin{array}{l}\text { Add } 28446 \\
\text { Autograft harvest is } \\
\text { included in this code even if } \\
\text { it is obtained from a distant } \\
\text { site (e.g., the knee) }\end{array}$ & 17.71 & 3.66 & 14.95 & 36.32 & 36.12 \\
\hline $\begin{array}{l}\text { w/open osteochondral ALLOgraft } \\
\text { transplant to talus }\end{array}$ & Add 28899 & - & - & - & - & - \\
\hline
\end{tabular}




\section{Case 3: (continued)}

\begin{tabular}{|l|l|l|l|l|l|l|}
\hline \multicolumn{1}{|c|}{ Procedure } & CPT Code & Work RVU & MP RVU & PE RVU & $\begin{array}{c}2022 \\
\text { Facility } \\
\text { Total RVU* }\end{array}$ & $\begin{array}{c}2021 \\
\text { Facility } \\
\text { Total RVU* }\end{array}$ \\
\hline $\begin{array}{l}\text { w/arthroscopic osteochondral } \\
\text { autograft transplant (OATs) to talus }\end{array}$ & Add 29999 & - & - & - & - & - \\
\hline $\begin{array}{l}\text { w/osteotomy (e.g., of medial } \\
\text { malleolus) for exposure to talus for } \\
\text { open OCD procedure }\end{array}$ & Procedures performed to gain exposure/access to the graft site are not separately codable \\
\hline $\begin{array}{l}\text { Arthroscopic lateral ankle ligament } \\
\text { repair (acute primary repair) }\end{array}$ & 29999 & - & - & - & - & - \\
\hline
\end{tabular}

